\title{
ROLE OF PROTONS IN CALCIUM SIGNALING
}

\author{
Giuliano Molinari ${ }^{1}, \mathrm{MSc}$ and Elsa $\mathrm{Nervo}^{2}$, MSc \\ ${ }^{1}$ Federazione Nazionale degli Ordini dei Chimici e dei Fisici, Rome, Italy \\ ${ }^{2}$ Società Chimica Italiana, Rome, Italy
}

\begin{abstract}
36 years after the publication of the important article by Busa and Nuccitelli on the variability of intracellular $\mathrm{pH}\left(\mathrm{pH}_{\mathrm{i}}\right)$ and the interdependence of $\mathrm{pH}_{\mathrm{i}}$ and intracellular $\mathrm{Ca}^{2+}$ concentration $\left(\left[\mathrm{Ca}^{2+}\right]_{\mathrm{i}}\right)$, little research has been carried out on $\mathrm{pH}_{\mathrm{i}}$ and calcium signaling. Moreover, the results appear to be contradictory.

Some authors claim that the increase in $\left[\mathrm{Ca}^{2+}\right]_{\mathrm{i}}$ is due to a reduction in $\mathrm{pH}_{\mathrm{i}}$, others that it is caused by an increase in $\mathrm{pH}_{\mathrm{i}}$.

The reasons for these conflicting results have not yet been discussed and clarified in an exhaustive manner.

Variations in $\mathrm{pH}_{\mathrm{i}}$ have a significant impact on the increase in $\left[\mathrm{Ca}^{2+}\right]_{\mathrm{i}}$ and hence on some of the basic biochemical mechanisms of calcium signaling. This paper focuses on the possible triggering role of protons, highlighting the mechanisms potentially involved and the open issues that could be clarified by research.
\end{abstract}

\section{Keywords}

Calcium-signaling; inositol-trisphosphate; $\mathrm{IP}_{3}$-mechanism; intracellular-pH; $\left[\mathrm{Ca}^{2+}\right]$; proton.

Corresponding Author address

E-Mail: giuliano.molinari@,fastwebnet.it 


\section{INTRODUCTION}

The value of intracellular $\mathrm{pH}\left(\mathrm{pH}_{\mathrm{i}}\right)$ is the measure of the concentration of protons in the cell $\left(\left[\mathrm{H}^{+}\right]_{\mathrm{i}}\right)$ and indicates the acid or alkaline nature of the cytoplasm. Normally, the $\mathrm{pH}_{\mathrm{i}}$ value is about 7.2, i.e. slightly alkaline. On the basis of experimental data, until the early 1980s, it was thought that the $\mathrm{pH}_{\mathrm{i}}$ value was essentially stable. In 1984, an invited opinion was published which dismantled this hypothesis and shifted the point of view on the question [Busa and Nuccitelli 1984].

Comparing a huge quantity of data from the publications then available, the authors showed that, on the contrary, $\mathrm{pH}_{\mathrm{i}}$ varies significantly. Their study includes a table [Busa and Nuccitelli 1984, Table 1] with numerous events in the life of a cell associated with variations in $\mathrm{pH}_{\mathrm{i}}$, including developmental transitions and stimulus-response coupling, in which calcium signaling is a fundamental step. After analyzing the experimental data, Busa and Nuccitelli declared that the intracellular concentration of $\mathrm{H}^{+}\left(\left[\mathrm{H}^{+}\right]_{\mathrm{i}}\right)$ is related to the intracellular concentration of $\mathrm{Ca}^{2+}\left(\left[\mathrm{Ca}^{2+}\right]_{\mathrm{i}}\right)$. Their results indicate correlations that are not always in the same direction, sometimes with trends that are unexpected or even the reverse of expectation. Indeed, they observe: "mounting evidence suggests that $\mathrm{pH}_{i}$ and $\mathrm{Ca}^{2+}$ changes can be interdependent, both in their mechanisms and their effects, although the significance of such interactions is still largely unclear".

Clearly, this is an important finding, both in general terms relating to cellular processes and specifically in relation to calcium signaling. And yet, after the publication of this paper, few articles appeared on the interdependence of concentrations of $\mathrm{pH}_{\mathrm{i}}$ and $\mathrm{Ca}^{2+}{ }_{\mathrm{i}}$ and the results were partly contradictory [Austin and Wray 2000] for reasons that are still unclear and deserve investigation for the purposes of clarification.

For some time, studies on the role of protons in cellular processes have taken into consideration the relationship between $\mathrm{pH}$ and calcium and its effects, in particular in relation to cellular channels and organelles. Protons modulate the action of various types of channel, including voltage-gated proton channels [DeCoursey 2018] which extrude protons, the Orai/STIM, transient receptor potential (TRP) channels [Yu 2018, Vangeel 2019], and two pore channels (TPC) [Kintzer 2018, Galione 2019] which foster $\mathrm{Ca}^{2+}$ influx via store-operated calcium entry (SOCE). Sarco-endoplasmic reticulum $\mathrm{Ca}^{2+}$-ATPase pump (SERCA) and the plasma membrane $\mathrm{Ca}^{2+}$-ATPase pump (PMCA) remove excess $\mathrm{Ca}^{2+}$ from the cytosol. The former conveys it to endo/sarcoplasmic reticular stores, the latter takes it outside the cell, exchanging it with a proton [Brini 2011, Hegedüs 2020]. The action of the PMCA would acidify the cytosol were it not for the counterbalancing action of the $\mathrm{Na}^{+} / \mathrm{H}^{+}$exchangers, which expel the proton in exchange for a $\mathrm{Na}^{+}$ion [Brini 2011, Xu 2015, Yang 2019]. The protons are also removed from the cytosol by various kinds of Vacuolar $\mathrm{H}^{+}$-ATPase pump (V-ATPase), which can transport them to the organelles or outside the cell, exchanging them with various cations, including $\mathrm{Ca}^{2+}$ [Fogarc 2007, Marshansky 2008, Colina-Tenorio 2018, Faris 2019]. The ATP which provides the energy required for the functioning of the PMCA and SERCA pumps is produced in the mitochondria by virtue of the protons, which - according to chemiosmotic theory - enable the entry of $\mathrm{Ca}^{2+}$ into the mitochondria [Pallafacchina 2018, Wilson 2019]. The proton gradient is the basis of the movement of the molecular rotary motors both in the mitochondria and the V-ATPases [Stewart 2015, Colina-Tenorio 2018].

Therefore, protons clearly play a fundamental role in metabolic processes, in particular in the organelles in which $\mathrm{Ca}^{2+}$ is accumulated. The cellular homeostasis of the calcium requires balance and continuous interchange between the organelles and the cytoplasm and between the latter and the extracellular space. This is possible only through the concerted action of the channels, pumps, and exchangers as described.

In relation to calcium signaling, it is believed that protons have a mainly regulatory role [Worley 1987, Donoso 1996, Poburko 2011, Raffaello 2016, Yu 2018, Yang 2019]. To our knowledge, no study attributes a triggering role to protons or makes an in-depth biochemical investigation of the interdependence mechanism between the $\mathrm{H}^{+}$and $\mathrm{Ca}^{2+}$ ions. Nonetheless, significant progress has been made over the past 40 years or so: several fundamental second messengers and pathways for 
calcium signaling have been identified [Pozzan 1994, Clapham 2007, Berridge 2012, Balla 2013, Carafoli 2016, Galione 2019], and the understanding of specific receptors [Rossi 2018, Prole 2019] and channels [Kozak and Putney 2017, Galione 2019] has improved. Experimental methods, particularly calcium imaging techniques, have been developed [Depaoli 2019, Siciliano 2019, Bischof 2019]. It has been shown that stimulus induces characteristic transient calcium blips, puffs (more generically known as calcium sparks or spikes) [Rose 2006], which in turn, through repetition, can give rise to calcium waves and oscillations [Dupont 2011, Gaspers 2014]. Despite this, some interactions between the various molecular players remain obscure [Raffaello 2016, Ribeiro 2018]. For example, we do not fully understand the biochemical mechanism by which second messengers such as inositol 1,4,5-trisphosphate $\left(\mathrm{IP}_{3}\right)$ mobilize the bound calcium of cellular stores, hence the resulting increase in $\left[\mathrm{Ca}^{2+}\right]_{\mathrm{i}}$ concentration and the appearance of calcium spikes. The origin of an important event such as " $\mathrm{Ca}^{2+}$ Induced $\mathrm{Ca}^{2+}$ Release" (CICR) is also unknown. To assess and understand the role of the molecular players involved, a better understanding of the biochemical mechanisms involved in their interactions is required. Specifically, further experimental research is needed to properly assess the importance of the variation in the intracellular concentration of protons $\left[\mathrm{H}^{+}\right] \mathrm{i}$, measured as a change in $\mathrm{pH}_{\mathrm{i}}$, in relation to the variation in intracellular $\mathrm{Ca}^{2+}$ concentration $\left(\left[\mathrm{Ca}^{2+}\right]_{i}\right)$ and the consequent activation of some enzymes.

\section{ABOUT OUR RESEARCH}

This work sets out to illustrate the biochemical mechanisms underlying $\mathrm{H}^{+} / \mathrm{Ca}^{2+}$ interconnections in the cell, focusing on the effects of variations in the concentration of protons on the change in $\left[\mathrm{Ca}^{2+}\right]_{\mathrm{i}}$ concentration. The chemical properties of the $\mathrm{H}^{+}$and $\mathrm{Ca}^{2+}$ ions, their interdependence and the effects at the cellular level suggest that protons have an active role in terms of stimulation, not only of control and regulation, and are therefore fundamental in calcium signal transmission. This hypothesis shows the mechanisms of calcium signaling in a new, broader perspective, and leads to a better understanding of numerous aspects and processes hitherto unclear.

Scientific literature available on-line from 1970 to January 2020 was drawn upon to analyze data and critically evaluate the fundamental concepts involved in the topic under study.

\section{3. $\mathrm{H}^{+} / \mathrm{Ca}^{2+}$ INTERDEPENDENCE}

\section{1. $\mathrm{H}^{+} / \mathrm{Ca}^{2+}$ interdependence in aqueous solution}

First, it is worth remembering that in aqueous solution, $\mathrm{H}^{+} / \mathrm{Ca}^{2+}$ interdependence is a direct consequence of the chemical properties of two elements, hydrogen and calcium. In its protonated form, hydrogen $\left(\mathrm{H}^{+}\right)$with anions give rise to acid molecules which are generally soluble in water. When $\mathrm{Ca}^{2+}$ binds with the anions, it forms salts, but unlike other positive ions such as $\mathrm{K}^{+}, \mathrm{Na}^{+}$and $\mathrm{NH}_{4}^{+}$which produce soluble salts, $\mathrm{Ca}^{2+}$ can give rise to insoluble salts [MacConaill 1985, RothBassel 1992, Periodic Table Solubility 2019]. For example, it is possible to verify in the lab that a solution of a sufficient quantity of $\mathrm{Ca}^{2+}$ in deionized water at alkaline $\mathrm{pH}$ is murky due to the formation of miniscule solid particles of insoluble salts suspended in the solution. This occurs because the $\mathrm{Ca}^{2+}$ binding to the $\mathrm{OH}^{-}$of the water and to the dissolved $\mathrm{CO}_{2}$ forms insoluble calcium hydroxide and calcium carbonate respectively. All the more, a solution containing ions physiologically present in the cell cytosol is murky because the $\mathrm{Ca}^{2+}$ binding to the inorganic (hydroxide, carbonate, phosphate, sulphate) and organic (oxalate, citrate, peptidate, proteinate) anions of the cytosol tends to form corresponding insoluble salts and complex compounds [Hincke 1978, MacConaill 1985, Iida 1986, Dubois 1990, Donoso 1996, Goss 2010]. The quantity of insoluble compounds formed which tends to precipitate depends on a number of factors: solubility 
product, ionic strength, ionic radius, coordination number, temperature and, above all, $\mathrm{pH}$. The solubility of calcium salts in water is $\mathrm{pH}$-dependent because the protons compete with the calcium for the same binding sites and can easily replace it. This replacement increases calcium-free $\mathrm{Ca}^{2+}$ in the solution reducing its murkiness. Therefore, adding a drop of acid with a concentration 10-20 times that of the total calcium present, it is possible to check quite easily for a reduction in murkiness and simultaneous increase in $\mathrm{Ca}^{2+}$ ions in the solution. This reaction, which can be seen by the naked eye, is transitory and localized, because it involves a volume that is just a little larger than the drop of acid added, and can therefore be described as a calcium spike on a macroscopic scale. To conclude, the murkiness increases when the $\mathrm{pH}$ is moved towards alkaline (=basic) values and decreases when the $\mathrm{pH}$ moves towards acid values. These localized and transitory variations in murkiness are evident even for small variations in $\mathrm{pH}$, especially when buffer systems are present as in the physiological-like solution. On the other hand soluble $\mathrm{Ca}^{2+}$-bound proteins do not produce murkiness; in these cases protons reduce the binding affinity of ligands and promote $\mathrm{Ca}^{2+}$ release. In conclusion, an increase in alkalinity (increase in $\mathrm{pH}$ ) fosters the formation and storage of bound calcium compounds and hence a decrease in the concentration of free calcium ions $\left[\mathrm{Ca}^{2+}\right]$, whilst an increase in acidity (decrease in $\mathrm{pH}$ ) fosters the solubilization/breaking of these compounds and hence an increase in $\mathrm{Ca}^{2+}$ concentration. Therefore, there is a direct chemical interdependence between $\mathrm{H}^{+}$and $\mathrm{Ca}^{2+}$ concentrations so, in a closed system, when one increases so does the other and vice versa. This direct and proportional interdependence between $\left[\mathrm{H}^{+}\right]$and $\left[\mathrm{Ca}^{2+}\right]$ has been shown experimentally in skeletal muscles [Donoso 1996] and in blood [McCudden 2013]. The relationship is shown by McCudden in Fig. 1, clearly illustrating the concept.

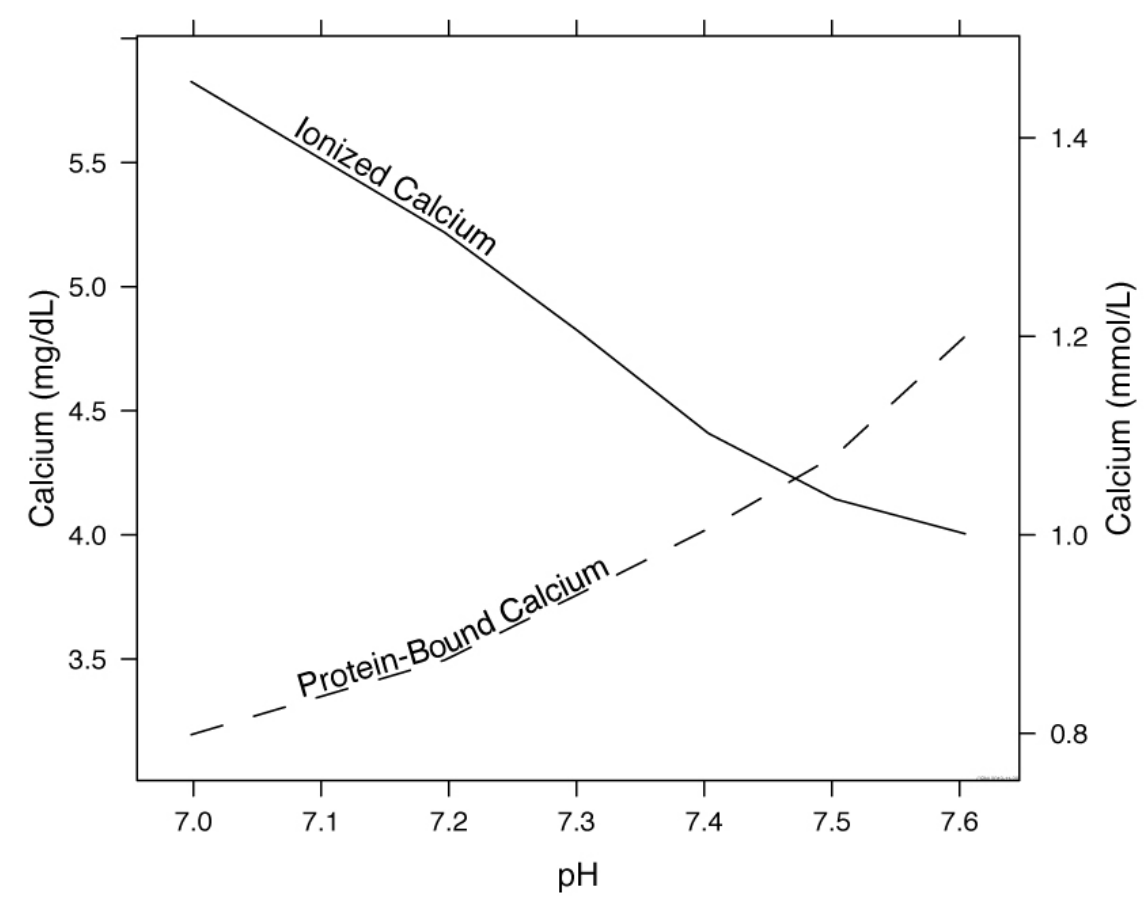

FIG. 1: The effect of $\mathrm{pH}$ on protein-bound and free calcium in blood. (By Christopher R. McCudden and reproduced here with kind permission of Radiometer). "As pH decreases, $\mathrm{H}^{+}$displaces $\mathrm{Ca}^{2+}$ from binding sites and the amount of free $\mathrm{Ca}^{2+}$ increases. Conversely, as the blood pH increases, albumin and the globulins become more negatively charged and bind more calcium, causing the amount of free $\mathrm{Ca}^{2+}$ circulating to decrease."

It is important to note that in aqueous solution, the above $\mathrm{pH}$-dependent reactions, i.e. calcium storage and calcium release may occur rapidly and spontaneously in the absence of biological structures, because they are the consequence of fundamental chemical laws. For example, it is 
possible to obtain the appearance of a calcium spike, on a macroscopic or microscopic scale, simply by localized acidification. To trigger the reactions of calcium storage and calcium release in aqueous solution, a $\mathrm{pH}$ change is sufficient, caused by any event that reduces or increases protons. A clear understanding of what can and cannot happen in aqueous solution due to the chemical interdependence between concentrations of $\mathrm{H}^{+}$and $\mathrm{Ca}^{2+}$ ions enables a more complete and coherent assessment of the data obtained experimentally due to variations in $\mathrm{pH}_{\mathrm{i}}$ in the cell.

\section{2. $\mathrm{H}^{+} / \mathrm{Ca}^{2+}$ interdependence in the cell}

The relationship between $\mathrm{H}^{+}$and $\mathrm{Ca}^{2+}$ integrated in the biochemical process inside the cell should be considered as part of the overall metabolic system of the cytoplasm.

It could be expected that, similarly to what occurs in an aqueous solution, the acidification of cellular cytosol always produces the depletion of calcium stores and consequently increases $\left[\mathrm{Ca}^{2+}\right]_{\mathrm{i}}$ concentration and that, on the other hand, alkalinization always produces the formation and storage of bound calcium and therefore decreases $\left[\mathrm{Ca}^{2+}\right]_{i}$ concentration. If this were the case, all the results of experimental studies on the effects of variations in $\mathrm{pH}_{\mathrm{i}}$ (decrease or increase of protons) on $\left[\mathrm{Ca}^{2+}\right]_{i}$ concentration in the cell would be consistent. But experiments have produced contrasting results. Some show that the increase in $\left[\mathrm{Ca}^{2+}\right]_{\mathrm{i}}$ is produced by acidification, in line with expectations given the chemical properties described above [Orchard 1987, Kim 1988, Cairns 1993, Daugirdas 1995, Donoso 1996, Nishiguchi 1997, Nagaoka 1997, González 1998, Balnave 2000, Chen 2001, Thomas 2002, Marin 2010, Krizaj 2011, Paillamanque 2016, Behera 2018, Berra-Romani 2019]. Other results, on the contrary, have shown that the increase in $\left[\mathrm{Ca}^{2+}\right]_{\mathrm{i}}$ is produced by alkalinization [Kiang 1991, Guse 1994, Nitschke 1996, Lindeman 1998, Minelli 2000, Alfonso 2000, Li 2012]. The situation in the cell is highly complex due to the presence of numerous biological structures (organelles, channels, pumps, receptors) which control and regulate ionic concentrations, in particular $\left[\mathrm{Ca}^{2+}\right]_{i}$ concentration, modifying them according to physiological needs. Physiological processes can influence $\mathrm{H}^{+} / \mathrm{Ca}^{2+}$ interdependence fostering or resisting it, pumping $\mathrm{H}^{+}$and/or $\mathrm{Ca}^{2+}$ outside the cell or in the organelles, and producing/consuming protons [Wacquier 2016, Raffaello 2016, Szymanski 2017, Faris 2019].

Therefore, in relation to the contrasting experimental results referred to above, it could be thought that a biochemical process, activated out of need by the cell, and hence extraordinarily, prevails over the ordinary chemical process producing a different result. This process should be identified and the reasons for the need explained. Only a few studies have provided an explanation by attributing the cause of the increase in $\left[\mathrm{Ca}^{2+}\right]_{\text {i }}$ produced by alkalinization to inhibition of the SERCA pump [Li 2012] or to a calcium influx [Lindeman 1998, Alfonso 2000, Minelli 2000]. To clarify this, some critical factors need to be taken into consideration, above all, response times. It is likely that studies of events with a medium/long-term response, such as those relating to situations of acidosis or alkalosis of the organism, involve mechanisms that are partly different from those with short-term responses. A medium/long-term response is more susceptible to outside influences and is more difficult to interpret, whilst a rapid response is usually sharper and clearer. The time between the stimulus and appearance/disappearance of the calcium spike is 5-10 s. The mean rise time of puffs is $19 \mathrm{~ms}$ and they are often preceded by trigger events with average durations of $\sim 12 \mathrm{~ms}$ [Rose 2006]. The speed of neutralization of an acid with a base is a matter of $\mu \mathrm{s}$ [Donten 2012] and the dissociation of a weak acid, i.e. the time for the release of an $\mathrm{H}^{+}$ion, is even quicker [Kanzaki 2014].

To identify and explain the mechanism underlying calcium signaling, it is therefore necessary to understand what happens in an extremely short time. At the experimental level, resources are required, specifically sensitive reagents and instruments able to respond to this speed of reaction. The reagents are the second critical factor, because they can produce interference, producing variations in the process. In studies of $\mathrm{H}^{+} / \mathrm{Ca}^{2+}$ interdependence, variations in $\mathrm{pH}_{\mathrm{i}}$ should be induced 
as far as possible physiologically, not by the introduction from outside of artifacts or acid compounds with buffering, chelating and/or permeabilizing effects or indicators that could modify the original $\mathrm{pH}_{\mathrm{i}}$ and $\left[\mathrm{Ca}^{2+}\right]_{\mathrm{i}}$ or the level of calcium bonded in cellular stores.

The third critical factor comprises the instruments and equipment used. Over the years, many different instruments and techniques have been used, often not dedicated and/or insufficiently sensitive. To overcome these limits, multiple complementary techniques and pharmacological manipulation are required [Bird 2018]. Chemical indicators, including Fluo-4 acetoxymethyl (AM), Rhod-2 AM, Fura-2 AM and the $\mathrm{Ca}^{2+}$ chelator BAPTA, commonly used over the past 25 years, are nowadays considered by some authors to be excessively invasive [Smith 2018]. But even modern genetically-encoded $\mathrm{Ca}^{2+}$ indicators have their problems [Bootman 2018, Yang 2018]. Given the different experimental methods, it is not surprising that the results are conflicting and not comparable.

The fundamental concepts acquired and currently shared by the scientific community in relation to calcium signaling are increasingly based on the key role of $\mathrm{Ca}^{2+}$ in the cell metabolism. For good ordinary functioning, the cell maintains a $\left[\mathrm{Ca}^{2+}\right]_{\mathrm{i}}$ concentration of $0.1 \mu \mathrm{M}$ [Bootman 2019] through the action of PMCA and SERCA pumps, which expel excess $\mathrm{Ca}^{2+}$ from the cytosol. The increase of $\left[\mathrm{Ca}^{2+}\right]_{\text {i from }} 0.1$ to $1 \mu \mathrm{M}$ and beyond, essential for the transmission of the signal, but excessive and potentially toxic for the cell, is an extraordinary and temporary event. This event is triggered by an external stimulus which, through the activation of a specific receptor, induces the release of a second messenger, in turn inducing calcium store depletion, the formation of calcium spikes and/or waves and, finally, calcium influx [Bootman 2019]. How the second messenger causes the release of $\mathrm{Ca}^{2+}$ from calcium stores, the formation of calcium spikes and increase in $\left[\mathrm{Ca}^{2+}\right]_{\mathrm{i}}$ concentration is unknown.

However, it may be that via the chemical properties of the $\mathrm{H}^{+}$and $\mathrm{Ca}^{2+}$ ions described in the section "3.1. $\mathrm{H}^{+} / \mathrm{Ca}^{2+}$ interdependence in aqueous solution", the protons freed by the second messenger [Molinari 2015] foster the release of calcium, replacing it in cellular stores. The following paragraph describes this hypothesis in detail, focusing on the $\mathrm{PLC} / \mathrm{IP}_{3}$ pathway.

\section{THE DUAL MOLECULAR MECHANISM FOR IP3 TRIGGERING}

The $\mathrm{PLC} / \mathrm{IP}_{3}$ pathway is triggered by an external stimulus, via agonist-receptor interaction on the plasmatic membrane, activating phospholipase C (PLC).

Generally, the receptor is in one of the following types: G-Protein-Coupled Receptors (GPCR), Tyrosine Kinase Receptors (RTK), or Tyrosine Kinase Non-Receptors (NRTK). In most cases, the PLCs belong to isoform PLC- $\beta$, PLC- $\gamma$, and PLC- $\varepsilon$ [Cocco 2015, Nakamura 2017].

All the phospholipases are heavily acidifying enzymes, because they hydrolytically split the lipid esters, producing an alcohol and an acid [Molinari 2019].

In particular, PLCs hydrolyze the phosphatidyl-inositol bisphosphate $\left(\mathrm{PIP}_{2}\right)$ into 1,2-diacylglycerol (DAG) plus $\mathrm{IP}_{3}$ [Michell 1981, Streb 1983]. The DAG is the alcohol and the $\mathrm{IP}_{3}$ the acid. The newly generated $\mathrm{IP}_{3}$ is protonated and has the following formula: $\mathrm{C}_{6} \mathrm{H}_{10} \mathrm{O}_{15} \mathrm{P}_{3}{ }^{5-}$.

$$
\mathrm{PIP}_{2}+\mathrm{H}_{2} \mathrm{O} \rightleftharpoons \mathrm{DAG}+\underset{\text { native } \mathrm{IP}_{3}\left(\mathrm{C}_{6} \mathrm{H}_{10} \mathrm{O}_{15} \mathrm{P}_{3}{ }^{5-}\right)}{\mathrm{IP}_{3}}
$$

The native $\mathrm{IP}_{3}$ must almost completely dissociate to bring itself into balance with the $\mathrm{pH}=7.2$ of the cytosol and hence quickly releases a proton:

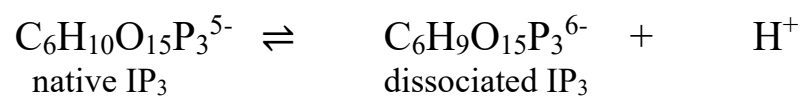


The protons produced by the dissociation of the $\mathrm{IP}_{3}$, following hydrolysis of $\mathrm{PIP}_{2}$, can reduce the affinity of $\mathrm{Ca}^{2+}$ for binders, such as inorganic anions or proteins, which immobilize it in the cytosol, and can foster the release of $\mathrm{Ca}^{2+}$ triggering rapid calcium spikes. It has been shown experimentally that the stimulus causes in the cytosol an increased concentration of protons and, in parallel, of $\mathrm{Ca}^{2+}$ [Kim 1988, Daugirdas 1995, Paillamanque 2016, Behera 2018, Berra-Romani 2019]. The cellular control mechanisms and first of all the cytosolic buffering capacity respond equally quickly, ending the spikes and returning the situation to a stationary state.

The rapid increase and subsequent decrease in $\left[\mathrm{Ca}^{2+}\right]$ i concentration, characteristic of transient calcium spikes, can be attributed to the chemical properties of the $\mathrm{H}^{+}$and $\mathrm{Ca}^{2+}$ ions and their interdependence, as shown by Busa and Nuccitelli.

Subsequently the $\mathrm{IP}_{3}$ spreads in the cytosol and reaches/activates its receptor $\left(\mathrm{IP}_{3} \mathrm{R}\right)$ on the membrane of the endoplasmic reticulum (ER). There are three types of $I_{3} R$ with quite similar characteristics [Vanderheyden 2009]. The activation of $\mathrm{IP}_{3} \mathrm{Rs}$ by $\mathrm{IP}_{3}$ induces the rapid release of $\mathrm{Ca}^{2+}$ from the calcium stores of the ER [Berridge 2012, Rossi 2018, Prole 2019].

Recent experimental studies have demonstrated that activation of the receptor required the presence not only of $\mathrm{IP}_{3}$ but of a certain amount of $\mathrm{Ca}^{2+}$ [Dellis 2006, Mak 2014]. The ability of calcium to stimulate the release of further calcium was observed for the first time in the 1970s, before the discovery of $\mathrm{IP}_{3}$. The phenomenon is known as $\mathrm{Ca}^{2+}$ Induced $\mathrm{Ca}^{2+}$ Release (CICR) and is discussed in detail below.

The molecular mechanism of CICR is unknown as is the gating mechanism of $\mathrm{IP}_{3} \mathrm{R}$ channels, activated by $\mathrm{IP}_{3}$, enabling the release of calcium from the endo/sarcoplasmic reticulum [Hamada 2018, Chandran 2019, Prole 2019].

The action of $\mathrm{IP}_{3}$ ends with its degradation by inositol phosphate phosphatases, in particular inositol polyphosphate-5-phosphatase A (5PTaseA) and Type II inositol 1,4,5-trisphosphate 5-phosphatase (5PTaseB), [Majerus 1992, Sims 1998, Balla 2013, Hsu 2015] which, in humans, are encoded by the INPP5A and INPP5B genes respectively.

The degradation of $\mathrm{IP}_{3}$ takes place by dephosphorylation and the main derivative is inositol 1,4bisphosphate [Lynch 1997]. Given that "termination enzymes" are considered of little importance, it is not surprising that 5PTaseA and 5PTaseB have not been studied extensively.

However, it is important to note that, like PLCs, phosphatases and hence also 5PTases, are strong acidifiers, because they hydrolyze phosphoric esters such as $\mathrm{IP}_{3}$ producing an alcohol - the inositol 1,4-bisphosphate - and inorganic acid phosphate. The reaction is as follows:

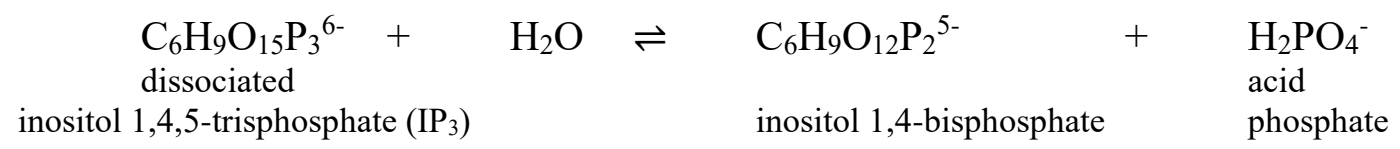

As soon as it is produced, the acid phosphate must dissociate almost completely to bring itself into balance with the $\mathrm{pH}$ of the cytosol and releases a proton, similarly to $\mathrm{IP}_{3}$ as described above.

$\mathrm{H}_{2} \mathrm{PO}_{4}^{-} \quad \rightleftharpoons \quad \mathrm{HPO}_{4}{ }^{2-} \quad+\quad \mathrm{H}^{+}$

Consequently, for the first time, we put forward the hypothesis that 5PTases, by degrading $\mathrm{IP}_{3}$ by hydrolysis, enable the action of $\mathrm{IP}_{3}$ when the hydrolysis ends, freeing protons, opening the $\mathrm{IP}_{3} \mathrm{R}$ channel and releasing $\mathrm{Ca}^{2+}$. Therefore, the $\mathrm{IP}_{3} \mathrm{R}$ channel would be a proton-gated channel. The membranes of the cellular organelles include some channels that could be proton-gated, such as:

- TRP channels; many TRP channels can be opened by acids and hence by protons [Numata 2011]; some interesting cases are known [Xu 2015, Vangeel 2019], for example lysosomal TRP channels which can be activated by an inositol 4,5-bisphosphate [Yang 2019]. 
- voltage-gated $\mathrm{Ca}^{2+}$ channels, for example of the two-pore channel type [Zhu 2010]; although the latter occur more in the acid organelles than in the ER.

In summary, the action of $\mathrm{IP}_{3}$ could take place in the cell, via the release of protons, at two different moments and in different points:

1) at the moment in which, via the PLCs, $\mathrm{IP}_{3}$ frees a limited but significant quantity of $\mathrm{H}^{+}$and $\mathrm{Ca}^{2+}$ on the inner side of the plasmatic membrane;

2) at the moment in which, via the $\mathrm{IP}_{3} \mathrm{R}$, it is degraded by the 5PTases on the outer side of the ER membrane or close by, with the consequent release of a larger quantity of $\mathrm{H}^{+}$and $\mathrm{Ca}^{2+}$.

The two events are not mutually exclusive, and are likely inter-related as well as related to the control mechanisms that activate the $\mathrm{Ca}^{2+}$ influx at the next phase of calcium signaling.

Since in some cells, such as oocytes, the 5PTases are mainly cytosolic enzymes and $\mathrm{IP}_{3} \mathrm{Rs}$ are present in various ways throughout the cytoplasm [Yoon 2019], it is possible that in some cases the activation of $\mathrm{IP}_{3} \mathrm{R}$ occurs in places other than that specified in point 2 above and involves the entire cytoplasmic space.

The hypothesis summarized above in points 1 and 2 is apparently simple, but has numerous implications. It is based on three fundamental and experimentally consolidated concepts:

- The activation of hydrolytic enzymes, such as phospholipases and phosphatases, produces acids.

- Via their protons, the acids foster the solubilization and release of bound calcium, freeing $\mathrm{Ca}^{2+}$.

- Due to the small size of the $\mathrm{H}^{+}$ion, protons are more mobile than $\mathrm{Ca}^{2+}$ and $\mathrm{IP}_{3}$.

The third concept may help to clarify the origin of calcium waves and oscillations. The $\mathrm{Ca}^{2+}$ ion has a large mass and ionic radius and, in addition, its movements in the cytoplasm are obstructed by the tendency to form salts and complex compounds that bind it 99\% [Prole 2019].

It was thought that $\mathrm{IP}_{3}$ was highly mobile and, spreading rapidly in the cytosol, was responsible for the formation of calcium waves. The topic is under discussion, because experimental measurements seem to indicate the opposite, i.e. that $\mathrm{IP}_{3}$ is not much more mobile than $\mathrm{Ca}^{2+}$ [Prole 2019].

On the other hand, the $\mathrm{H}^{+}$ion has a low mass and very small ionic radius and cannot be immobilized easily because it tends to give rise to soluble compounds. The discussion above, about the dissociation of $\mathrm{IP}_{3}$, indicated the extremely high speed of the reactions freeing and consuming protons. Furthermore, the speed of movement of the protons in the cell has been measured and compared to the speed of sound [Fitchl 2016].

Therefore, protons have all the chemical and physical characteristics required for them to be a basis for the formation of calcium waves and oscillations.

\section{CONTROL AND FEEDBACK}

The various systems of calcium signaling are interconnected and control each other by the modulation of numerous $\mathrm{Ca}^{2+}$-dependent enzyme activities including phospholipases, phosphatases, kinases, and phosphorylases, as well as the action of second messengers such as $\mathrm{IP}_{3}$, cAMP and NAADP. It should be remembered that cAMP and NAADP are phosphoric esters and via hydrolysis can free protons similarly to $\mathrm{IP}_{3}$ [Molinari 2015].

The intensity of the stimulus induces diverse effects giving rise to both spatial and temporal modifications of the signal, with important functional consequences [Samanta 2017]. 
In these processes, the levels of $\left[\mathrm{Ca}^{2+}\right]_{i}$ concentration are a subtle discriminant. Generally there is a direct proportion between $\left[\mathrm{Ca}^{2+}\right]_{i}$ and biological activity, but this is not always the case. In particular, $\mathrm{IP}_{3} \mathrm{Rs}$ receptors are subject to biphasic regulation by $\left[\mathrm{Ca}^{2+}\right] \mathrm{i}$; studies have demonstrated that the activity of all $\mathrm{IP}_{3} \mathrm{Rs}$ is boosted by slight increases in $\left[\mathrm{Ca}^{2+}\right]_{\mathrm{i}}$ and is inhibited by significant increases [Iino 1990; Bezprozvanny et al. 1991; Foskett et al. 2007, Prole 2019]. To protect itself from the risk that very rapid cellular biochemical processes, such as those involved in $\mathrm{Ca}^{2+}$ signaling, evade control, the organism carries out a number of different mechanisms. For example, due to the immediate increase in PLC activity because of its $\mathrm{Ca}^{2+}$-dependence, the chain reaction of the $\mathrm{PLC} / \mathrm{IP}_{3}$ pathway (the hydrolysis of $\mathrm{PIP}_{2}-$ generation of $\mathrm{IP}_{3}$ - liberation of protons - release in the cytosol of $\mathrm{Ca}^{2+}$ - the increase in $\mathrm{Ca}^{2+}$-dependent phospholipase activity) could give rise to a self-sustained and self-stimulating closed circuit with the risk of an exponential increase in its activity were it not for control action with the opposite effect.

This action is carried out by phosphorylating enzymes, kinases and phosphorylases, which have the function of reconstructing the estero-phosphoric bindings previously split.

Consequently, the activation of phosphorylating enzymes also produced by the increase in $\left[\mathrm{Ca}^{2+}\right] \mathrm{i}$ fosters biochemical processes that go in the opposite direction to the reactions of the catalyzed hydrolysis of the phospholipases and phosphatases as described above.

The action of phosphatidyl inositol phosphate kinase (PIPK) opposes that of PLC [Sun 2013], whilst the various kinases control the phosphatases by the synthesis of an array of inositol trisphosphate $\left(\mathrm{IP}_{3}\right)$ and tetrakisphosphate $\left(\mathrm{IP}_{4}\right)$ molecules in the cytosol [Irvine 2001, Shears 2004, Bunney 2010, Irvine 2016, Anguita 2018].

The opposing action must take place rapidly and with sufficient force, conditions guaranteed by the fact that phosphorylating enzymes are no less $\mathrm{Ca}^{2+}$-dependent than the phospholipases and phosphatases.

Furthermore, for control to be effective, the opposing actions must comprise a balanced biochemical system, i.e. they must take place simultaneously. It has already been suggested that $\mathrm{PIP}_{2}$ hydrolysis is stimulated concomitant with its synthesis [Loew 2007].

It could also be thought that the action of the phospholipases and phosphatases takes place alternately with that of the phosphorylating enzymes, in a rapid sequence of repeated hydrolysis and synthesis and that this could explain the appearance of the oscillations characteristic of calcium signaling [Salazar 2008]. However, the phosphorylating enzymes act via chemical and biochemical mechanisms which are substantially different: the kinases transfer the phosphoric group of the ATP to the substrate, whilst the phosphorylases introduce the inorganic phosphoric group into the substrate.

To sustain alternance, it would be useful to show that the acidification produced by the hydrolysis is followed by alkalinization produced by the synthesis, i.e. proof that at least one of the two types of synthesis reaction, either the one catalyzed by the kinases or the one catalyzed by the phosphorylases, is able to remove protons from the system and hence to alkalinize the cytosol. This, in addition to the effect of cytosolic buffering described above, might be a more adequate explanation of the oscillations characteristic of calcium signaling.

The topic deserves investigation and clarification.

\section{THE CICR PHENOMENON}

" $\mathrm{Ca}^{2+}$ Induced $\mathrm{Ca}^{2+}$ Release" (CICR) was discovered by studying the biochemical system of the cellular activity of the muscles [Ford 1970, Endo 1977, Endo 2009] and was defined as " $\mathrm{Ca}^{2+}$ release by the action of $\mathrm{Ca}^{2+}$ alone without the simultaneous action of other activating processes" [Endo 2009]. 
Therefore, it is the mechanism by which a small increase in cytosolic $\mathrm{Ca}^{2+}$ is able to induce the release of $\mathrm{Ca}^{2+}$ from the cellular stores of the endo/sarcoplasmatic reticule reaching significant $\left[\mathrm{Ca}^{2+}\right]_{\mathrm{i}}$ concentrations.

The cellular process of CICR has been confirmed experimentally on numerous occasions both for excitable and non-excitable cells. The phenomenon can occur by involvement of two types of receptors, $\mathrm{IP}_{3} \mathrm{Rs}$ and ryanodine receptors (RyR) [Endo 2009, Laver 2018]. It has been experimentally demonstrated that both the $\mathrm{IP}_{3} \mathrm{Rs}$ and the RyRs can be activated by $\mathrm{H}^{+}$. However, the molecular mechanism of the process by which CICR activates the gating of $\mathrm{IP}_{3} \mathrm{R}$ and RyR channels has yet to be clarified.

The description of the metabolic phenomenon that occurs in the cellular cytoplasm is paradoxical from the biochemical point of view. It is known from the common ion effect that the addition of the same ion in a solution decreases its solubility. Therefore, the action described by the acronym CICR seems difficult to carry out from a purely ionic standpoint.

Nonetheless, given $\mathrm{H}^{+} / \mathrm{Ca}^{2+}$ interdependence, there are two possible mechanisms for the gating of the $\mathrm{IP}_{3} \mathrm{R}$ and RyR channels.

A - In the simplest case, it could be thought that the small increase in the cytosolic $\mathrm{Ca}^{2+}$ activating the CICR is a consequence and indicator of a parallel increase in $\mathrm{H}^{+}$, caused by the unconscious intervention of an operator, for example by introducing a buffer or reagent. Therefore, it is $\mathrm{H}^{+}$and not $\mathrm{Ca}^{2+}$ that causes the gating of the $\mathrm{IP}_{3} \mathrm{R}$ and RyR channels. Since the mechanism is exclusively chemical, no other activating process is required.

B - The second hypothesis presupposes the presence of an as yet undetected biological process that partially or totally modifies the cellular homeostasis of the calcium. For example, it could be thought that the small increase in cytosolic $\mathrm{Ca}^{2+}$ activates $\mathrm{Ca}$-dependent phospholipases or phosphatases, which in turn produces the release of $\mathrm{H}^{+}$and hence the opening of the channels. Indeed, some authors have come to this conclusion to explain a phenomenon similar to CICR observed in smooth muscles [Ureña 2013].

The two hypotheses, A) and B) are not mutually exclusive and could occur simultaneously.

\section{CONCLUSION}

This work investigates some possible, important consequences of $\mathrm{H}^{+} / \mathrm{Ca}^{2+}$ interdependence in relation to calcium signaling. Given the chemical properties of these two ions and starting from the hypothesis that protons may have a stimulatory and not only regulatory role in the cell, it is possible to discuss the process in a new and broader manner and to posit biochemical explanations for the mechanisms causing some fundamental steps, which for some time have defied clarification. New connections can be suggested for the well-known events that occur, as established experimentally, in the process of calcium signaling, and a plausible and coherent picture can be built up for the basic mechanism involved.

Above all, it has been shown that the enzymatic activity of the phospholiphases and phosphatases frees protons. Investigations have been carried out into the ability of the protons to:

- generate calcium spikes and oscillations;

- trigger the gating of $\mathrm{IP}_{3} \mathrm{Rs}$ and RyRs;

- induce CICR. 
In our opinion these three important cytoplasmic activities carried out by the enzymatically produced protons are made possible by the particular chemical and physical characteristics of the protons themselves: very small, highly mobile, with a rapid reaction and ability to replace $\mathrm{Ca}^{2+}$ in its binding sites. These considerations are reason enough to posit the activation and not merely regulatory role of protons in calcium signaling. A significant role, that could be indispensable in two fundamental steps in the transduction of the signal: the release of bound $\mathrm{Ca}^{2+}$ and gating of $\mathrm{IP}_{3} \mathrm{R}$ and RyR receptors. Therefore, it is important for the first time to present the basic events in the mechanism of calcium signaling within the general framework set out above.

The biochemical reactions involved in the production/consumption of protons inside the cell should be studied in depth. Among these, of particular interest are esterifications and the enzymes that catalyze them, in both directions, i.e. those of hydrolysis and synthesis. Enzymes such as phospholipases, phosphatases, kinases, and phosphorylases may significantly modify the levels of free calcium and hence all the spatial and temporal aspects of the related signal. Clearly, to carry out experiments into the processes in which protons play an important role, it is necessary to maintain the strictest control over $\mathrm{pH}$ and the buffering capacity of the materials under examination.

Recent progress in calcium imaging techniques should bring to light the biochemical data and steps relating to the various processes and confirm the hypothesis set out above. 


\section{REFERENCES}

Alfonso, A., Cabado, A. G., Vieytes, M. R. and Botana, L. M. (2000). Calcium-pH crosstalks in rat mast cells: cytosolic alkalinization, but not intracellular calcium release, is a sufficient signal for degranulation. British Journal of Pharmacology, 130 (8): 1809-1816.

Anguita, E. and Villalobo, A. (2018). $\mathrm{Ca}^{2+}$ signaling and Src-kinases-controlled cellular functions. Archives of Biochemistry and Biophysics, 650: 59-74. doi: 10.1016/j.abb.2018.05.005.

Austin, C. and Wray, S. (2000). Interactions Between $\mathrm{Ca}^{2+}$ and $\mathrm{H}^{+}$and Functional Consequences in Vascular Smooth Muscle. Circulation Research, 86 (3): 355-363.

Balla, T. (2013). Phosphoinositides: Tiny Lipids With Giant Impact on Cell Regulation. Physiological Reviews, 93 (3): 1019-1137.

Balnave, C. D. and Vaughan-Jones R. D. (2000). Effect of intracellular pH on spontaneous $\mathrm{Ca}^{2+}$ sparks in rat ventricular myocytes. The Journal of Physiology, 528 (1): 25-37.

Behera, S., Xu, Z., Luoni, L., Bonza, M. C., Doccula, F. G., De Michelis, M. I., Morris, R. J., Schwarzländer, M. and Costa, A. (2018). Cellular $\mathrm{Ca}^{2+}$ Signals Generate Defined $\mathrm{pH}$ Signatures in Plants. The Plant Cell, 30: 2704-2719.

Berra-Romani, R., Faris, P., Negri, S., Botta, L., Genova, T. and Moccia, F. (2019). Arachidonic Acid Evokes an Increase in Intracellular $\mathrm{Ca}^{2+}$ Concentration and Nitric Oxide Production in Endothelial Cells from Human Brain Microcirculation. Cells, 8: 689. doi:10.3390/cells8070689

Berridge, M. J. (2012). Calcium signalling remodelling and disease. Biochemical Society Transactions, 40 (2): 297-309.

Bezprozvanny, I., Watras, J. and Ehrlich, B. E. (1991). Bell-shaped calcium-response curves for Ins(1,4,5)P3- and calcium-gated channels from endoplasmic reticulum of cerebellum. Nature, 351: $751-754$.

Bird, G. S. and Putney, W. J. jr. (2018). "Pharmacology of Store-Operated Calcium Entry Channels." In Calcium Entry Channels in Non-Excitable Cells, edited by Kozak, J. A. and Putney, J. W. jr. Methods in signal transduction series. Boca Raton (FL): CRC Press, Taylor \& Francis Group, Chapter 16. doi: 10.1201/9781315152592-16

Bischof, H., Burgstaller, S., Waldeck-Weiermair, M., Rauter, T., Schinagl, M., Ramadani-Muja, J., Graier, W. F. and Malli, R. (2019). Live-Cell Imaging of Physiologically Relevant Metal Ions Using Genetically Encoded FRET-Based Probes. Cells, 8 (5): E492.

Bootman, M. D., Allman, S., Rietdorf, K. and Bultynck, G. (2018). Deleterious effects of calcium indicators within cells; an inconvenient truth. Cell Calcium, 73: 82-87.

Bootman, M. D. and Bultynck, G. (2019). Fundamentals of Cellular Calcium Signaling: A Primer. Cold Spring Harbor Perspectives in Biology, doi: 10.1101/cshperspect.a038802.

Brini, M. and Carafoli, E. (2011). The plasma membrane $\mathrm{Ca}^{2+}$ ATPase and the plasma membrane sodium calcium exchanger cooperate in the regulation of cell calcium. Cold Spring Harbor Perspectives in Biology, 3 (2): a004168. doi: 10.1101/cshperspect.a004168. 
Bunney, T. D. and Katan, M. (2010). Phosphoinositide signalling in cancer: beyond PI3K and PTEN. Nature Reviews Cancer, 10 (5): 342-52.

Busa, W. B. and Nuccitelli, R. (1984). Metabolic regulation via intracellular pH. American Journal of Physiology. 246 (4 Pt 2): R409-38. https://doi.org/10.1152/ajpregu.1984.246.4.R409.

Cairns, S.P., Westerblad, H. and Allen, D. G. (1993). Changes in myoplasmic pH and calcium concentration during exposure to lactate in isolated rat ventricular Myocytes. Journal of Physiology, 464: 561-574.

Carafoli, E. and Krebs, J. 2016. Why calcium? How Calcium Became the Best Communicator. The Journal of Biological Chemistry, 291 (40): 20849-20857.

Chandran, A., Chee, X., Prole, D. L. and Rahman, T. (2019). Exploration of inositol 1,4,5trisphosphate (IP3) regulated dynamics of N-terminal domain of $\mathrm{IP}_{3}$ receptor reveals early phase molecular events during receptor activation. Scientific Reports, 9 (1): 2454.

Chen, W-H., Chen, C-H., Yang, K-T., Chang, W-L., Su, M-J., Wu, C-C. and Wu, M-W. (2001). Arachidonic acid-induced $\mathrm{H}^{+}$and $\mathrm{Ca}^{2+}$ increases in both the cytoplasm and nucleoplasm of rat cerebellar granule cells. The Journal of Physiology, 537 (2): 497-510.

Clapham, D. E. (2007). Calcium signaling. Cell, 131 (6): 1047-58.

Cocco, L., Follo, M., Manzoli, L. and Suh P-G. (2015). Phosphoinositide-specific phospholipase C in health and disease. Journal of Lipid Research, 56 (10): 1853-1860.

Colina-Tenorio, L., Dautant, A., Miranda-Astudillo H., Giraud, M. F. and Gonzàlez-Halphen, D. (2018). The peripheral Stalk of Rotary ATPases. Frontiers in Physiology, 9: 1243.

Daugirdas, J. T., Arrieta, X., Ye, M., Flores, G. and Batile, D. C. (1995). Intracellular Acidification Associated with Changes in Free Cytosolic Calcium. Evidence for $\mathrm{Ca}^{2+} / \mathrm{H}^{+}$Exchange via a Plasma Membrane $\mathrm{Ca}^{2+}$-ATPase in Vascular Smooth Muscle Cells. The Journal of Clinical Investigation, 95 (4): 1480-1489.

DeCoursey, T. E. (2018). Gating currents indicate complex gating of voltage-gated proton channels. Proceedings of the National Academy of Science, 115 (37): 9057-9059.

https://doi.org/10.1073/pnas.1813013115

Dellis, O., Dedos, S. G., Tovey S. C., Taufiq-Ur-Rahman, Dubel, S. J. and Taylor, C. W. (2006). $\mathrm{Ca}^{2+}$ entry through plasma membrane $\mathrm{IP}_{3}$ receptors. Science, 313 (5784): 229-33.

Depaoli, M. G., Bischof, H., Eroglu, E., Burgstaller, S., Ramadani-Muja, J., Rauter, T., Schinagl, M. et al. (2019). Live cell imaging of signaling and metabolic activities. Pharmacology\& Therapeutics, Jun 7. pii: S0163-7258(19)30110-X. https://doi.org/10.1016/j.pharmthera.2019.06.003

Donoso, P., Beltrán, M., and Hidalgo, C. (1996). Luminal pH Regulates Calcium Release Kinetics in Sarcoplasmic Reticulum Vesicles. Biochemistry, 35 (41): 13419-13425.

Donten, M. L., Vandevondele, J. and Hamm, P. (2012). Speed limits for acid-base chemistry in aqueous solutions. Chimia International Journal for Chemistry, 66 (4): 182-186.

Dubois, I. and Gerday, C. 1990. Soluble calcium-binding proteins: parvalbumins and calmodulin from eel skeletal muscle. Comparative Biochemistry and Physiology B, 95 (2): 381-5. 
Dupont, G., Combettes, L., Bird, G. S., and Putney, J. W. (2011) Calcium Oscillations. Cold Spring Harbor Perspectives in Biology, 3 (3): a004226.

Endo, M. (1977). Calcium release from the sarcoplasmic reticulum. Physiological Reviews, 57: 71108.

Endo, M. (2009). Calcium-Induced Calcium Release in Skeletal Muscle. Physiological Reviews, 89: 1153-1176.

Faris, P., Shekha, M., Montagna, D., Guerra, G. and Moccia, F. (2019). Endolysosomal $\mathrm{Ca}^{2+}$ Signalling and Cancer Hallmarks: Two-Pore Channels on the Move, TRPML1 Lags Behind!Cancers, 11, 27.

Fogarc, M. (2007). Vacuolar ATPases: rotary proton pumps in physiology and pathophysiology. Nature Reviews Molecular Cell Biology, 8 (11): 917-929.

Ford, L.E. and Podolsky, R.J. (1970). Regenerative calcium release within muscle cells. Science, 167: 58-59.

Foskett, J. K., White, C., Cheung, K. H. and Mak, D.O. (2007). Inositol trisphosphate receptor $\mathrm{Ca}^{2+}$ release channels. Physiological Reviews, 87: 593-658.

Galione, A. (2019). NAADP Receptors. Cold Spring Harbor Perspectives in Biology, pii: a035071. doi: $10.1101 /$ cshperspect.a035071.

Gaspers, L. D., Bartlett, P. J., Burnett, P., Metzger, W., Johnston, J., Joseph, S. K., Höfer, T. and Thomas, A. P. (2014). Hormone-induced calcium oscillations depend on cross-coupling with inositol 1,4,5-trisphosphate oscillations. Cell Reports, 9: 1209-18.

González, A., Pfeiffer, F., Schmid, A., and Schulz, I. (1998). Effect of intracellular pH on acetylcholine-induced $\mathrm{Ca}^{2+}$ waves in mouse pancreatic acinar cells. American Journal of Physiology Cell Physiology, 275: C810-C817.

Goss, F., Prushko, J. and Bogner, R. (2010). Factors affecting calcium precipitation during neutralisation in a simulated intestinal environment. Journal of Pharmaceutical Science, 99 (10): 4183-91.

Guse, A. H., Roth, E. and Emmrich, F. (1994). $\mathrm{Ca}^{2+}$ release and $\mathrm{Ca}^{2+}$ entry induced by rapid cytosolic alkalinization in Jurkat T-lymphocytes. Biochemical Journal, 301 (1): 83-88.

Hamada, K., Miyatake, H., Terauchi, A. and Mikoshiba, K. (2017). IP 3 -mediated gating mechanism of the $\mathrm{IP}_{3}$ receptor revealed by mutagenesis and X-ray crystallography. Proceedings of the National Academy of Sciences of the United States of America, 114 (18): 4661-4666.

Hegedüs, L. et al. (2020). Molecular Diversity of Plasma Membrane Ca2+ Transporting ATPases: Their Function Under Normal and Pathological Conditions. In: Islam M. (eds) Calcium Signaling. Advances in Experimental Medicine and Biology, vol 1131. Springer, Cham

Hincke, M. T., McCubbin, W. D. and Kay, C. M. (1978). Calcium-binding properties of cardiac and skeletal troponin $\mathrm{C}$ as determined by circular dichroism and ultraviolet difference spectroscopy, Canadian Journal of Biochemistry, 56 (178): 384-95. 
Hsu, FS. and Mao, Y. (2015). The structure of phosphoinositide phosphatases: Insights into substrate specificity and catalysis. Biochimica et Biophysica Acta, 1851 (6): 698-710.

Iida, S. and Potter, J. D. (1986). Calcium binding to calmodulin. Cooperativity of the calciumbinding sites. The Journal of Biochemistry, 99(6):1765-1772.

https://doi.org/10.1093/oxfordjournals.jbchem.a135654.

Iino, M. (1990). Biphasic $\mathrm{Ca}^{2+}$ dependence of inositol 1,4,5-trisphosphate-induced $\mathrm{Ca}^{2+}$ release in smooth muscle cells of the guinea pig taenia caeci. Journal of General Physiology, 95: 1103-1122.

Irvine, R. F. (2016). A short history of inositol lipids. In Thematic Review Series: Living History of Lipids. Journal of Lipid Research, 57 (11): 1987-1994.

Irvine, R. F., and Schell, M. J. (2001). Back in the water: the return of the inositol phosphates. Nature Reviews Molecular Cell Biology, 2: 327-338.

Kanzaki, Y., Tokuda, K. and Bruckensteinc, S. (2014). Dissociation Rates of Weak Acids Using Sinusoidal Hydrodynamic Modulated Rotating Disk Electrode Employing Koutecky-Levich Equation. Journal of The Electrochemical Society, 161 (12): H770-H779.

Kiang, J. G. (1991). Effect of intracellular $\mathrm{pH}$ on cytosolic free $\left[\mathrm{Ca}^{2+}\right]$ in human epidermoid A-431 cells. European Journal of Pharmacology: Molecular Pharmacology, 207 (4): 287-296.

Kim, D. and Smith, T. W. (1988). Cellular mechanisms underlying calcium-proton interactions in cultured chick ventricular cells. Journal of Physiology, 398: 391-410.

Kintzer, A. F., Stroud, R. M. (2018). On the structure and mechanism of two-pore channels. The FEBS Journal, 285(2):233-243.

Kozak, J.A. and Putney, J.W. jr. editors. (2017). Calcium Entry Channels in Non-Excitable Cells. Methods in signal transduction series. Boca Raton (FL): CRC Press.

Krizaj, D., Mercer, A. J., Thoreson, W.B. and Barabas, P. (2011). Intracellular pH modulates inner segment calcium homeostasis in vertebrate photoreceptors. American Journal of Physiology Cell Physiology, 300 (1): C187-C197.

Laver, D. R. (2018). Regulation of the RyR channel gating by $\mathrm{Ca}^{2+}$ and $\mathrm{Mg}^{2+}$. Biophysical Reviews, 10:1087-1095. https://doi.org/10.1007/s12551-018-0433-4.

Li, S., Hao, B., Lu, Y., Yu, P., Lee, H. C. and Yue, C. (2012). Intracellular Alkalinization Induces Cytosolic $\mathrm{Ca}^{2+}$ Increases by Inhibiting Sarco/Endoplasmic Reticulum $\mathrm{Ca}^{2+}$-ATPase (SERCA). PloS One, 7 (2): e31905.

Lindeman, K. S., Croxton, T. L., Lande, B. and Hirshman, C. A. (1998). Hypocapnia-induced contraction of porcine airway smooth muscle. European Respiratory Journal, 12 (5): 1046-1052.

Loew, L. M. (2007). Where does all the $\mathrm{PIP}_{2}$ come from? The Journal of Physiology, 582 (3): 945951.

Lynch, B. J., Muqit, M. M. K., Walker, T. R. and Chilvers, E. R. (1997). [3H]Inositol Polyphosphate Metabolism in Muscarinic Cholinoceptor-Stimulated Airways Smooth Muscle: Accumulation of [3H]inositol 4,5 Bisphosphate Via a Lithium-Sensitive Inositol Polyphosphate 1-Phosphatase. Journal of Pharmacology and Experimental Therapeutics, 280 (2) 974-982. 
MacConaill, M. (1985). Calcium precipitation from mammalian physiological salines (Ringer solutions) and the preparation of high [Ca] media. Journal of Pharmacological Methods, 14 (2): 147-55. https://doi.org/10.1016/0160-5402(85)90052-X

Majerus, P. W. (1992). Inositol phosphate biochemistry. Annual Review of Biochemistry, 61: 225250.

Mak, D.-O. O. and Foskett, J. K. (2015). Inositol 1,4,5-trisphosphate Receptors in the Endoplasmic Reticulum: a Single-channel Point of View. Cell Calcium, 58 (1): 67-78. doi:10.1016/j.ceca.2014.12.008

Marin, M., Sellier, C., Paul-Antoine, A. F., Cailliau, K., Browaeys-Poly, E., Bodart, J. F. and Vilain, J. P. (2010). Calcium Dynamics During Physiological Acidification in Xenopus Oocyte. The Journal of Membrane Biology, 236 (3): 233-245.

Marshansky, V. and Futai, M. (2008). The $V$-type $H^{+}$-ATPase in vesicular trafficking: targeting, regulation and function. Current Opinion in Cell Biology, 20 (4): 415-26.

https://doi.org/10.1016/j.ceb.2008.03.015

McCudden, C. R. (2013). pH-adjusted ionized calcium. Accessed August 4, 2019. Article downloadable from acutecaretesting.org. https://acutecaretesting.org/en/articles/ph-adjustedionized-calcium.

Michell, R.H., Kirk, C.J., Jones, L.M., Downes, C.P. and Creba, J. A. (1981). The stimulation of inositol lipid metabolism that accompanies calcium mobilization in stimulated cells: defined characteristics and unanswered questions. Philosophical Transactions of the Royal Society B, 296 (1080): 123-137. doi 10.1098/rstb.1981.0177.

Minelli, A., Lyons, S., Nolte, C., Verkhratsky, A. and Kettenmann, H. (2000). Ammonium triggers calcium elevation in cultured mouse microglial cells by initiating $\mathrm{Ca}(2+)$ release from thapsigarginsensitive intracellular stores. Pflügers Archiv: European Journal of Physiology, 439 (3): 370-7.

Molinari, G. (2015). Is hydrogen ion $(\mathrm{H}(+))$ the real second messenger in calcium signalling? Cellular Signalling, 27 (7): 1392-7.

Molinari, G. and Nervo, E. (2019). Phospholipases cause transient increases of $\mathrm{H}^{+}$and $\mathrm{Ca}^{2+}$ concentrations. [version 1; not peer reviewed]. F1000Research, 8:270 (poster) https://doi.org/10.7490/f1000research.1116471.1

Nagaoka, T., Masuda, A. and Takamatsu, T. (1997). Lowering Extracellular pH Raises Intracellular Calcium in Cultured Rat Astrocytes. Acta Histochemica et Cytochemica, 30 (2): 221-225.

Nakamura, Y. and Kiyoko, F. (2017). Regulation and physiological functions of mammalian phospholipase C. Journal of Biochemistry, 161 (4): 315-321.

Nishiguchi, H., Hayashi, T., Shigetomi, T., Ueda, M. and Tomita, T. (1997). Changes in Intracellular $\mathrm{Ca}^{2+}$ Concentration Produced by the Alteration of Intracellular $\mathrm{pH}$ in Rat Parotid Acinar Cells. Japanese Journal of Physiology, 47: 41-49.

Nitschke, R., Riedel, A., Ricken, S., Leipziger, J., Benning, N., Fischer, K. G. and Greger, R. (1996). The effect of intracellular $\mathrm{pH}$ on cytosolic $\mathrm{Ca}^{2+}$ in HT29 cells. Pflügers Archiv: European Journal of Physiology, 433 (1-2): 98-108. 
Numata, T., Kiyonaka, S., Kato, K., Takahashi, N. and Mori Y. (2011). “Activation of TRP Channels in Mammalian Systems" In TRP Channels, edited by Zhu, M. X. Boca Raton (FL): CRC Press, Taylor \& Francis, Chapter 3.

Orchard, C. H., Houser, S.R., Kort, A.A., Bahinski, A., Capogrossi, M. C. and Lakatta, E. G. (1987). Acidosis Facilitates Spontaneous Sarcoplasmic Reticulum $\mathrm{Ca}^{2+}$ Release in Rat Myocardium. Journal of General Physiology, 90 (1): 145-165.

Paillamanque, J., Madrid, C., Carmona, E. M., Osses, N., Moreno, R. D., Oresti, G. M., Pino, J. A. and Reyes, J. G. (2016). Effects of Fatty Acids on Intracellular $\left[\mathrm{Ca}^{2+}\right]$, Mitochondrial Uncoupling and Apoptosis in Rat Pachytene Spermatocytes and Round Spermatids. PloS One, 11 (7): e0158518.

Pallafacchina, G., Zanin, S. and Rizzuto, R. (2018). Recent advances in the molecular mechanism of mitochondrial calcium uptake. [version 1; peer review: 4 approved] F1000Research 2018, 7 (F1000 Faculty Rev): 1858. https://doi.org/10.12688/f1000research.15723.1

Periodic table of elements org. n.d. "Solubility table." Accessed August 4, 2019. https://periodictable-of-elements.org/SOLUBILITY.

Poburko, D., Santo-Domingo, J., and Demaurex, N. (2011). Dynamic Regulation of the Mitochondrial Proton Gradient during Cytosolic Calcium Elevations. The Journal of Biological Chemistry, 286 (13): 11672-11684.

Pozzan, T., Rizzuto, R., Volpe, P. and Meldolesi, J. (1994). Molecular and cellular physiology of intracellular calcium stores. Physiological Reviews, 74 (3): 595-636.

Prole, D.L. and Taylor, C.W. (2019). Structure and Function of $\mathrm{IP}_{3}$ Receptors. Cold Spring Harbor Perspectives in Biology, 11 (4). pii: a035063. doi: 10.1101/cshperspect.a035063.

Raffaello, A., Mammucari, C., Gherardi, G., and Rizzuto, R. (2016). Calcium at the center of cell signaling: interplay between endoplasmic reticulum, mitochondria and lysosomes. Trends in Biochemical Science, 41 (12): 1035-1049.

Ribeiro, D., Freitas, M., Rocha, S., Lima, J. L. F. C., Carvalho, F. and Fernandes, E. (2018). Calcium Pathways in Human Neutrophils-The Extended Effects of Thapsigargin and ML-9. Cells, 7 (11): E204.

Rose, H. J., Dargan, S., Shuai, J. and Parker, I. (2006). 'Trigger' Events Precede Calcium Puffs in Xenopus Oocytes. Biophysical Journal, 91: 4024-4032.

Rossi, A.M., Taylor, C.W. (2018). $\mathrm{IP}_{3}$ receptors - lessons from analyses ex cellula. Journal of Cell Science, 132: jcs222463. doi: 10.1242/jcs.222463.

Roth-Bassel, H. A. and Clydesdale, F. M. (1992). In Vitro Solubility Characteristics of Six Calcium Salts. Journal of Food Protection, 55 (12): 1003-1005. https://doi.org/10.4315/0362_028X_ 55.12.1003.

Salazar, C., Politi, A. Z. and Höfer, T. (2007). Decoding of calcium oscillations by phosphorylation cycles: analytic results. Biophysical Journal, 94 (4): 1203-15.

Samanta, K. and Parekh, A. B. (2017). Spatial $\mathrm{Ca}^{2+}$ profiling: decrypting the universal cytosolic $\mathrm{Ca}^{2+}$ oscillation. The Journal of Physiology, 595: 3053-3062. 
Shears, S. B. (2004). How versatile are inositol phosphate kinases? Biochemical Journal, 377: 265280 .

Siciliano, C. A. and Tye, K. M. (2019). Leveraging calcium imaging to illuminate circuit dysfunction in addiction. Alcohol, 74: 47-63.

Sims, C. E. and Allbritton, N. L. (1998). Metabolism of inositol 1,4,5-trisphosphate and inositol 1,3,4,5-tetrakisphosphate by the oocytes of Xenopus laevis. The Journal of Biological Chemistry, 273 (7): 4052-8.

Smith, N. A., Kress, B. T., Lu, Y., Chandler-Militello, D., Benraiss, A. and Nedergaard, M. (2018). Fluorescent $\mathrm{Ca}^{2+}$ indicators directly inhibit the Na,K-ATPase and disrupt cellular functions. Science Signaling, 11 (515): eaal2039. doi: 10.1126/scisignal.aal2039.

Stewart, A. G., Laming, E. M., Sobti, M. and Stock D. (2014). Rotary ATPases - dynamic molecular machines. Current Opinion in Structural Biology, 25: 40-48.

Streb, H., Irvine, R.F., Berridge, M.J. and Schulz, I. (1983). Release of $\mathrm{Ca}^{2+}$ from a nonmitochondrial intracellular store in pancreatic acinar cells by inositol-1,4,5-trisphosphate. Nature, 306 (5938): 67-9.

Sun, Y., Thapa, N., Hedman, A. C. and Anderson, R. A. (2013). Phosphatidylinositol-4,5bisphosphate: Targeted Production and Signaling. Bioessays, 35 (6): 10.1002/bies.201200171.

Thomas, R. C. (2002). The Effects of $\mathrm{HCl}$ and $\mathrm{CaCl}_{2}$ Injections on Intracellular Calcium and $\mathrm{pH}$ in Voltage-clamped Snail (Helix aspersa) Neurons. Journal of General Physiology, 120 (4): 567-579. doi: 10.1085 /jgp.20028665

Ureña, J., Fernández-Tenorio, M., Porras-Gonzáles, C., González-Rodríguez, P., Castellano, A. and López-Barneo, J. (2013). A new metabotropic role for L-type $\mathrm{Ca}(2+)$ channels in vascular smooth muscle contraction. Current Vascular Pharmacology, 11 (4): 490-6.

Vanderheyden, V., Devogelaere, B., Missianen, L., De Smedt, H., Bultynck, G. and Parys, J. B. (2009). Regulation of inositol 1,4,5-trisphosphate-induced $\mathrm{Ca}^{2+}$ release by reversible phosphorylation and dephosphorylation. Biochimica et Biophysica Acta, 1793 (6): 959-970.

Vangeel, L. and Voets, T. (2019). Transient Receptor Potential (TRP) Channels and Calcium Signaling. Cold Spring Harbor Perspectives in Biology, 11 (6): a035048.

Wilson, C., Lee, M. D., Heathcote, H. R., Zhang, X., Buckley, C., Girkin J. M., Saunter, C. D., and McCarron, J. G. (2019). Mitochondrial ATP production provides long-range control of endothelial inositol trisphosphate-evoked calcium signaling. The Journal of Biological Chemistry, 294 (3): $737-758$.

Worley, P. F., Baraban, J. M., Supattapone, S., Wilson, V. S. and Snyder, S. H. (1987). Characterization of inositol trisphosphate receptor binding in brain. Regulation by $\mathrm{pH}$ and calcium. The Journal of Biological Chemistry, 262: 12132-12136.

Xu, H., Martinoia, E. and Szabo, I. (2015). Organellar Channels and Transporters. Cell Calcium, 58 (1): 1-10. https://doi.org/10.1016/j.ceca.2015.02.006.

Yang, J., Zhao, Z., Gu, M., Feng, X. and Xu, X. (2019). Release and uptake mechanisms of vesicular $\mathrm{Ca}^{2+}$ stores. Protein \& Cell, 10 (1): 8-19. https://doi.org/10.1007/s13238-018-0523-X 
Yang, Y., Liu, N., He, Y., Liu, Y., Ge, L., Zou, L., Song, S., Xiong, W. and Liu, X. (2018). Improved calcium sensor GCaMP-X overcomes the calcium channel perturbations induced by the calmodulin in GcaMP. Nature Communications, 9 (1): 1504. doi: 10.1038/s41467-018-03719-6.

Yoon, S. Y. (2019). Role of Type 1 Inositol 1,4,5-triphosphate Receptors in Mammalian Oocytes. Development \& Reproduction, 23 (1): 1-9.

Yu, A. S., Yue, Z., Feng, J. and Yue, L. (2018). "Regulation of Orai/STIM Channels by pH.” In Calcium Entry Channels in Non-Excitable Cells, edited by Kozak, J. A., and Putney, J. W. jr. Methods in signal transduction series. Boca Raton (FL): CRC Press, Taylor \& Francis Group, 9: 161-176.

Zhu, M. X., Mab, J., Parrington, J., Galione, A. and Evans, M. (2010). TPCs: Endolysosomal channels for $\mathrm{Ca}^{2+}$ mobilization from acidic organelles triggered by NAADP. Febs Letters, 584 (10): 1966-1974. 